\title{
Wasteless Splitting of Metal Round Bars Basing on Cross-Wedge Rolling Process
}

Arkadiusz Tofil(PL) atofil@pwsz.chelm.pl

Zbigniew Pater(PL) z.pater@pollub.pl

\section{BIOGRAPHICAL NOTES}

Arkadiusz Tofil, Ing. PhD. (born in 1975) Assistant professor in the Department of Computer Modeling and Metal Forming Technologies at the Lublin University of Technology and Vice-Rector for Development and International Relations at the State School of Higher Education in Chełm. He graduated from the faculty of Mechanical Engineering at the Lublin University of Technology in 2001. Professional specialization it is mainly forming of metals, technology of cross-wedge rolling, bar cropping without waste, modelling and computer simulation.

\section{KEY WORDS}

Bar Splitting, Cross-Wedge Rolling, Experiment

\section{ABSTRACT}

This paper presents research works on a new method of wasteless splitting of metal round bars. This method is connected with rolling on the bar circumference of a groove in the shape of letter $\mathrm{V}$, and, later, on repeated rotary bending of the bar separate part, leading to the metal cracking. Special tools sets, in which a flat-wedged rolling mill LUW-2 used at the Lublin University of Technology was equipped with, were applied in the splitting process. A typical set includes: mounting, cutting knife and bending pad. Laboratory tests confirmed the effectiveness of the worked out splitting method. This process was also analyzed theoretically, basing on finite element method (FEM). In calculations, the influence of process basic parameters on the cracking process was analyzed: knife forming angle, rolled groove depth, bending angle and length of the cut bar part. The possibility of brittle fracture (on the basis of Saint-Venant hypothesis) and ductile fracture (on the basis of Cockroft-Latham) presence was analyzed.

\section{INTRODUCTION}

Different kinds of devices are used for round metal bars cutting, depending on production and metal type. Basically applied cutting methods can be divided into cutting with waste and without waste.

In recent years, at the Department of Computer Modeling and Metal Forming at Lublin University of Technology, research works [1,2] on a new method of wasteless splitting of round metal bars have been carried out. This method is connected with making on the bar circumference of a V-groove, and later, on repeated rotary bending of the bar separate part, leading to metal cracking.

Cross-wedge rolling process in cold conditions (CWR) was used for V-groove making on the bar circumference. Detailed description of research works dealing with this 
process is presented in paper [2]. Due to a research stand for CWR, research works were limited to rolling method by means of flat wedges. Two ways of groove forming (Fig. 1) were considered. In the first way (Fig. 1a), called free CWR, contact with metal is only in the area of the formed necking. In the second way (Fig. 1b), called CWR with compression, tools contact with the billet also outside the forming zone. Additionally in Fig. 1, the most important parameters of the analyzed process CWR were shown.

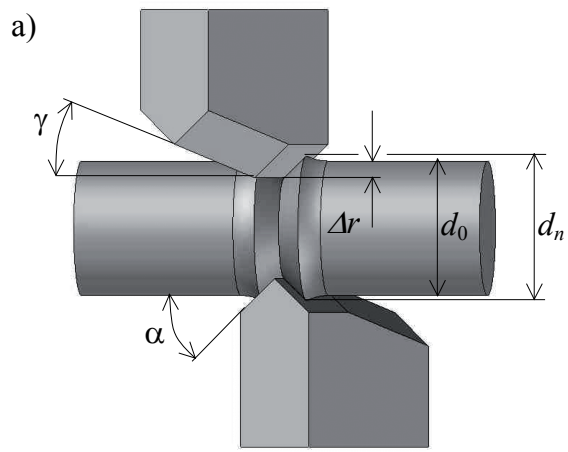

b)

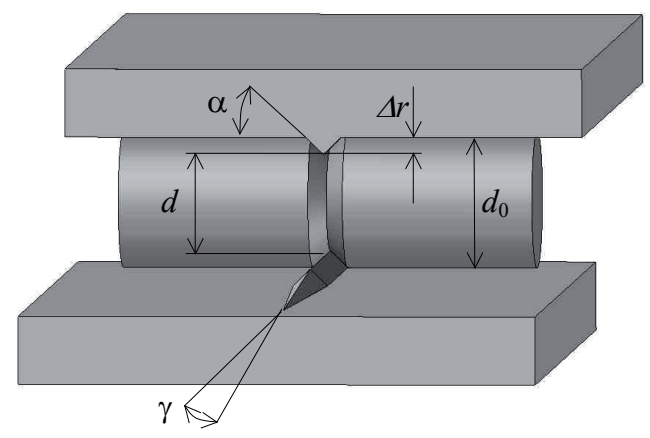

Fig. 1 Analyzed within the scope of research works method of cross rolling of $\mathrm{V}$-grooves on the workpiece circumference: a) local contact (free (WR), b) contact on the tool whole length (CWR with compression)

\section{On the basis of the conducted research works it was} stated that:

the application of the CWR in cold allows for forming of V-groove on the bar circumference; the rolling process can be realized by means of two ways: free CWR method (contact between tools and material is only in the area of formed necking) and CWR method with compression (contact tool- material is on the billet whole width);

- strains in the groove area are of laminar character (in form of ring layers) and reach maximal values in external surfaces;

during free CWR metal is upset before the wedge, which leads to the increase of the rolled bar diameter. The upsetting value depends on the applied forming angle $\alpha$;

forming forces value depends on CWR process parameters. Forces undergo reduction together with the application of larger angles $\alpha$ and smaller reduction ratio $\Delta r$;

- CWR process stability can be limited in the result of uncontrolled slip and rolled bar rupture presence. The best forming conditions, in order to avoid the mentioned earlier distur-bances, are obtained when the applied tools have forming angles $\alpha=45^{\circ}$. This paper discusses the results of the further research stage dealing with bars cracking during splitting without waste. The research scope included laboratory tests of splitting of bars from steel C45 and numerical analysis basing on finite element method (FEM).

\section{Laboratory tests of wasteless splitting process}

Experimental research of the splitting without waste process of round metal bars were done at Lublin University of Technology using flat-wedge rolling mill LUW-2 (Fig. 2). For the research needs, tools sets with the length $500 \mathrm{~mm}$ and width $120 \mathrm{~mm}$ were made (shown schematically in Fig. 3). Each tool set consists of a knife (wedge) and a bending pad which are placed in mounting. The knife is used for rolling of V-groove on the bar circumference. However, bending pads are responsible for rotary bending of the bar split part of length $l$. In Fig. 3 main parameters of the splitting without waste process are also presented: bending angle $\theta$, forming angle $\alpha$, reduction ratio $\Delta r$. In research processes knives with angles $\alpha=45^{\circ}$ and $60^{\circ}$ were used, which cut into the bar at the depth $\Delta r=2$ $\mathrm{mm}$. Two sets of bending pads were also used for which $\theta=45^{\circ}$ and $3^{\circ}$.

Bars with diameters $\varnothing 20 \mathrm{~mm}$ and length $200 \mathrm{~mm}$ were split. The conducted research concerned splitting of bars from steel $\mathrm{C} 45$ type. On the basis of compression tests, a curve of the used steel type was determined and described by means of the following dependency: 
$\sigma_{p}=1041.4 \varphi_{i}^{0.201}$

where $\sigma_{\mathrm{p}}$ - yield stress $\varphi_{\mathrm{i}}$ - effective strain.

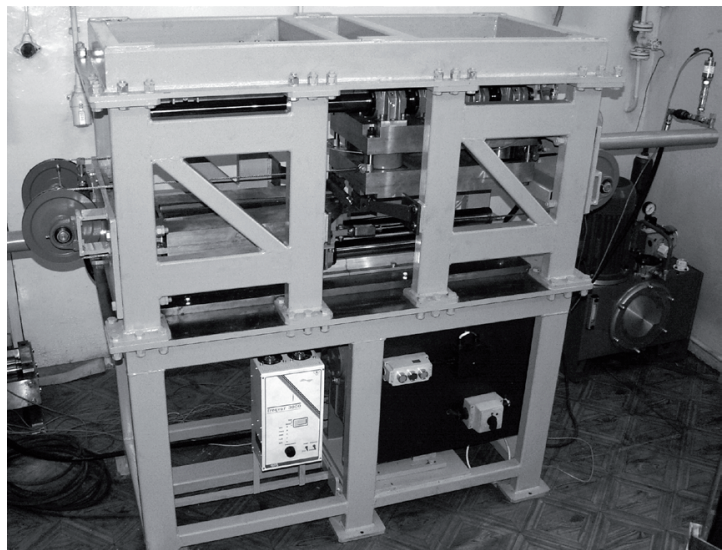

Fig. 2 Laboratory stand LUW-2 for CWR with two flat wedges

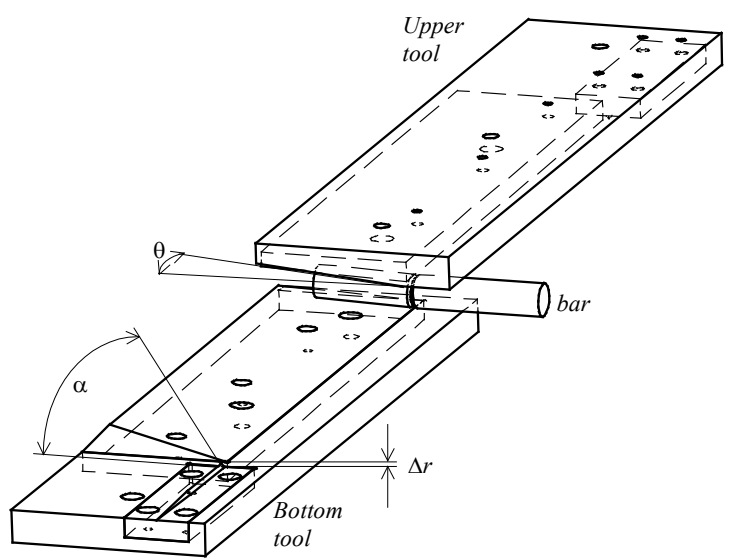

Fig. 3 Schema of analyzed process of wasteless splitting

On the basis of tensile tests the following parameters of the applied steel $\mathrm{C} 45$ were deter-mined: tensile strength $R_{\mathrm{m}}=697 \mathrm{MPa}$, yield point $R_{\mathrm{e}}=$ $439 \mathrm{MPa}$, unit elongation $A_{10}=19,1 \%$. Yet, basing on ring-sample upsetting, the friction factor for friction pair steel $\mathrm{C} 45$-tool steel was determined and it was equal $m=0,5$.

Experimental research were realized at rolling tools spacing $20 \mathrm{~mm}$. The splitting test course was as follow: the billet together with sleeve was placed in the rolling mill feeder. Next, tools were put into motion (with linear velocity $\nu=0,1 \mathrm{~m} / \mathrm{s}$ ) and splitting process was realized at given parameters $(\theta, \alpha)$ and reduction ratio $\Delta r=2 \mathrm{~mm}$. In the case when the bar did not undergo splitting, it was removed from the container and tools were also backtracked, and again after billet positioning the splitting process was repeated.

In the result of stand tests the rightness of the analyzed conception of round metal bars splitting was confirmed - Fig. 4. It was stated that application of this method allows for splitting from bar of parts with minimal length 1.3 bar diameter $d_{0}$.

Two characteristic zones at the splitting surface can be distinguished: external (shiny) - appearing during rolling of V-groove and internal (mat) - appearing during metal cracking. Moreover, on the basis of conducted laboratory stand tests it was stated that metal cracking has a spiral character (from the external to the bar axis) - Fig. 4. Yet, the largest the bending angle $\theta$ value, the smaller the number of bar rotation (at the bending stage) is required for metal splitting.

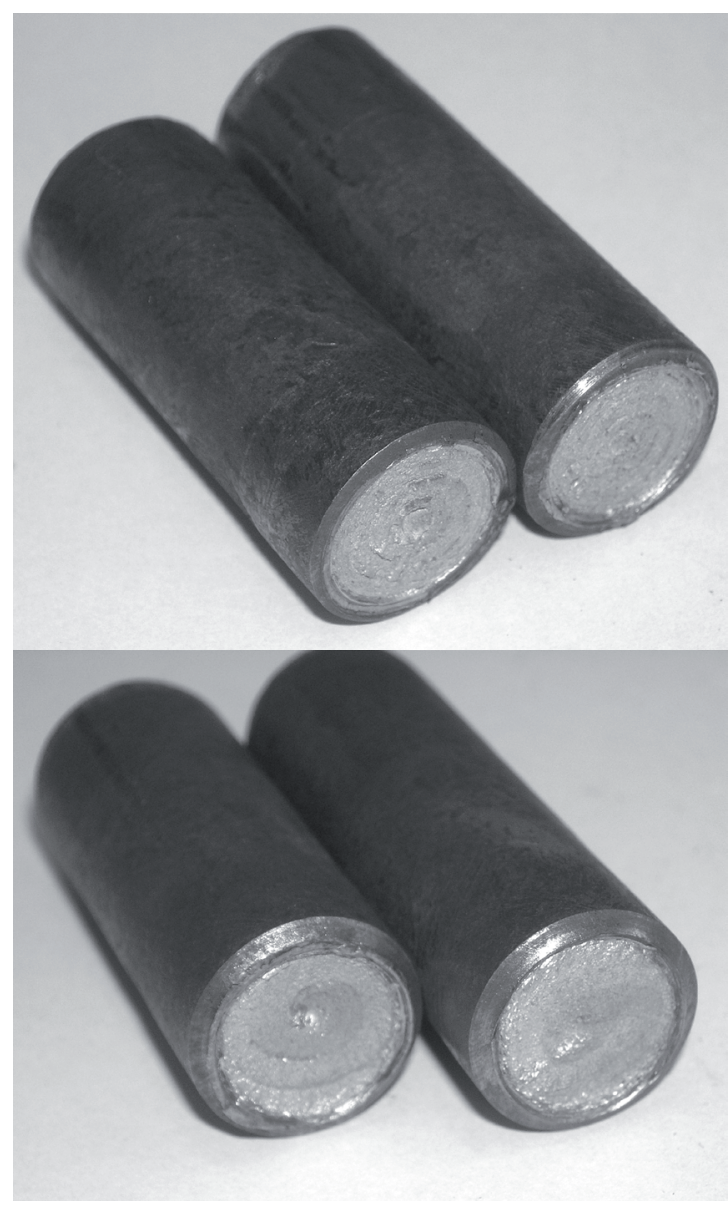

Fig. 4 C45 steel grade elements obtained during wasteless splitting process at: $\alpha=45^{\circ}, \Delta r=2 \mathrm{~mm}, \theta=2^{\circ}$ (upper figure) or $\theta=3^{\circ}$ (bottom figure) 


\section{Numerical analysis of metal cracking in splitting process}

Numerical analysis of metal cracking in splitting without waste process was made applying the commercial software MSC.SuperForm 2005 basing on FEM. Calculations were made assuming that split bars were of steel C45 type. It was assumed that material model of the formed metal is described by the dependency (1). In the analysis thermo - mechanical schema of calculations was used, assuming that bar and tools temperature was the same as the environment temperature $20^{\circ} \mathrm{C}$. At the same time, it was assumed that heat exchange coefficient between tools and metal was $20 \mathrm{~kW} / \mathrm{m}^{2} \mathrm{~K}$ and between metal and environment $0,2 \mathrm{~kW} / \mathrm{m}^{2} \mathrm{~K}$. In simulations, model of shear friction was used, which depends on the metal slip vs. tool and is determined by friction factor $\mathrm{m}=0,5$.

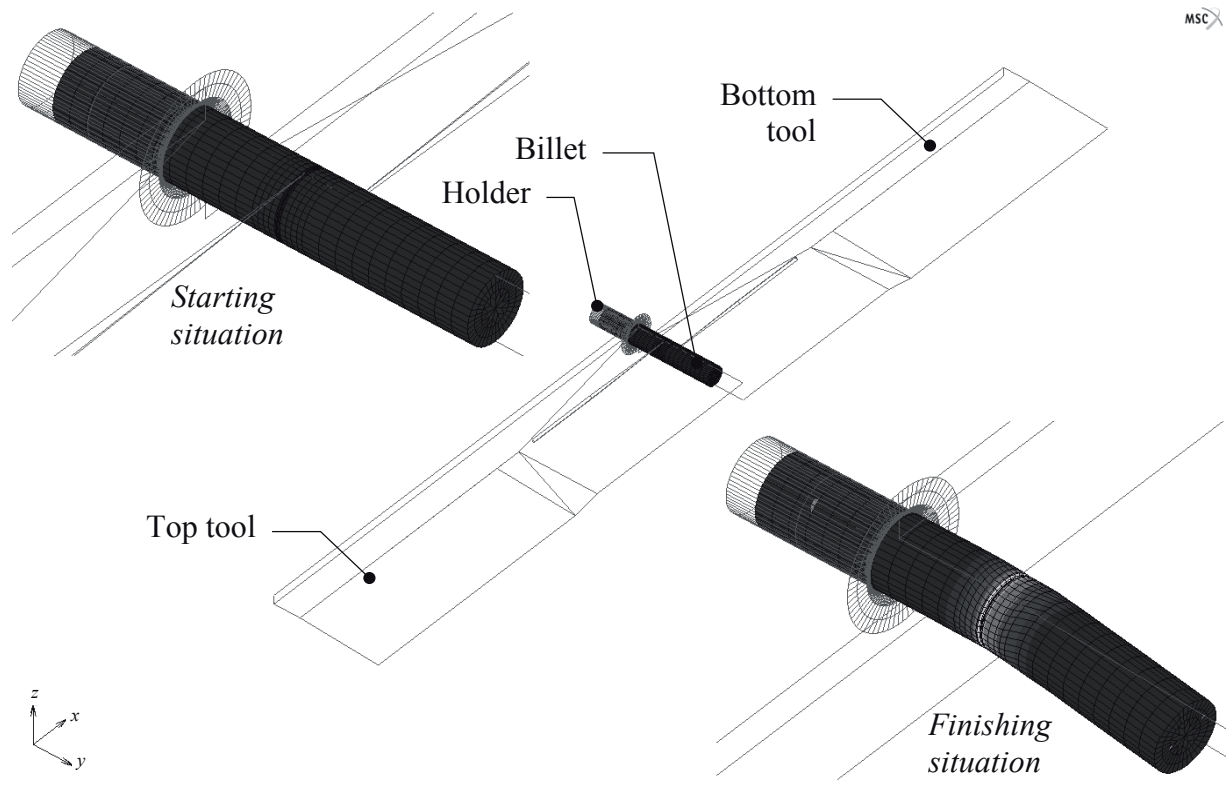

Fig. 5 FEM model of wasteless splitting process realized at $\triangle r=2 \mathrm{~mm}, \alpha=45^{\circ}, d_{0}=20 \mathrm{~mm}$ and $\theta=3^{\circ}$

\section{Numerical analysis was made assuming the following simplifications:}

- tools behave as perfect rigid body, tools edges rounding is not important in splitting process and it can be omitted,

friction factor on material-tools surface of contact is constant and does not change during the process.

After considering of the mention above simplifications several FEM models of splitting without waste process were worked out, one of them is shown in Fig. 5. Each model consists of a bar from steel C45 (with diameter $d_{0}=20 \mathrm{~mm}$ ), two tools sets moving in the opposite directions with velocities $\nu=0,1 \mathrm{~m} / \mathrm{s}$ - upper and lower, and mounting device positioning bar during rolling.

In calculations the following parameters were changed: forming angle $\left(\alpha=45^{\circ} ; 50^{\circ}\right.$ and $\left.60^{\circ}\right)$, bending angle $\left(\theta=2^{\circ} ; 3^{\circ}\right.$ and $\left.4^{\circ}\right)$, reduction ratio
( $\Delta r=1,5 \mathrm{~mm} ; 2,0 \mathrm{~mm}$ and $2,5 \mathrm{~mm})$ and rolling length ( $l=20 \mathrm{~mm} ; 30 \mathrm{~mm}$; and $57,5 \mathrm{~mm}$ ). Remeshing was not used in calculations due to retaining of full information about state of strain in nodes.

The rightness of finite element method application in the analysis of cross-wedge rolling process (including CWR of V-groove in cold conditions) was confirmed by results of tests verifying calculations, made in laboratory and industrial conditions [1]. It can be then assumed that this method will be also adequate for the analysis of splitting without waste process. This is confirmed by comparison of tangent forces (directed according to tools movement), calculated by FEM and measured in laboratory conditions, shown in Fig. 6 and considering one of the analysed splitting cases. This comparison shows good qualitive and quantitive conformity between the noticed forces distributions. 


\section{Brittle fracture}

Influence of state of stress on cracking is described by condition of brittle fracture as in the equation [3]:

$$
\sigma_{z r}=R_{m}
$$

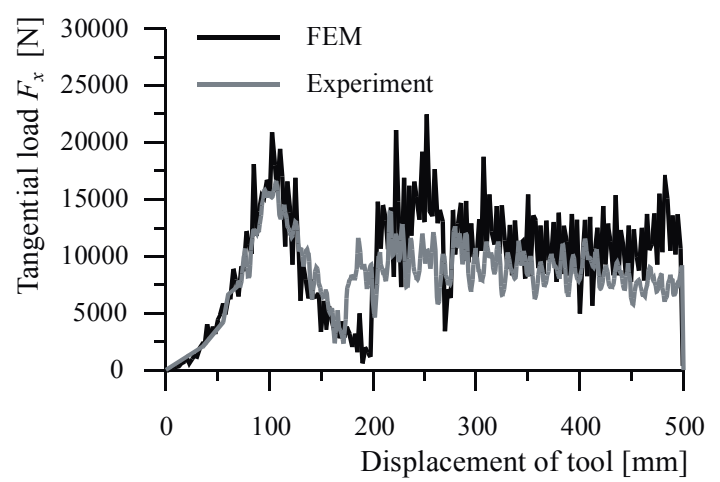

Fig. 6 Comparison of tangential loads (acting in tools movement direction) in wasteless splitting process of $\mathrm{C} 45$ steel bar, at: $d_{0}=20 \mathrm{~mm}, \Delta r=2 \mathrm{~mm}, \alpha=45^{\circ}$ and $\theta=3^{\circ}$

In the above equation $R_{\mathrm{m}}$ means tensile strength, $\sigma_{\mathrm{zr}}$ - reduced stress that can be defined e.g on the basis of hypothesis of the largest elongation as:
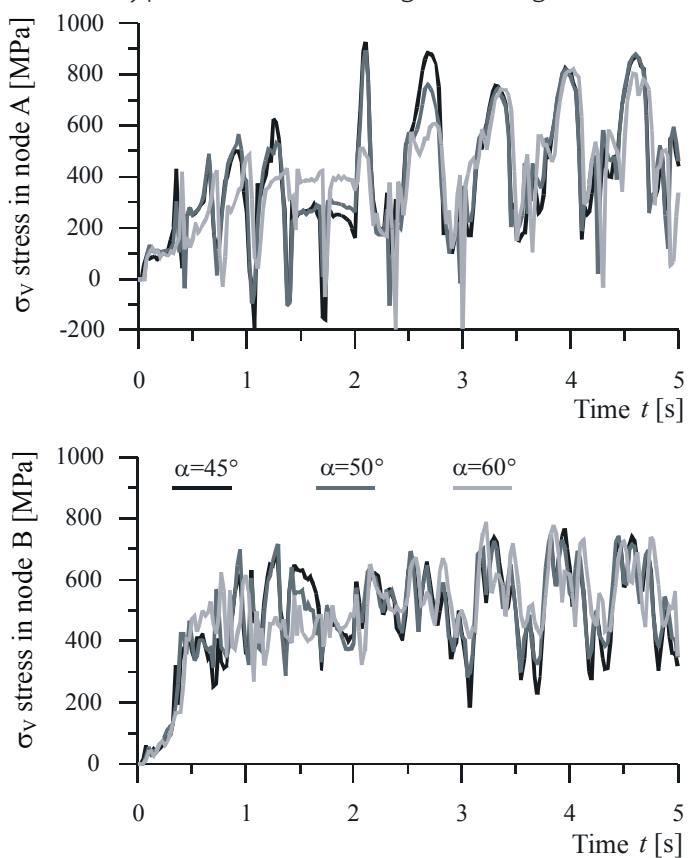

Fig. 7 Influence of forming angle $\alpha$ on $\sigma v$ during wasteless splitting process of C45 steel bar at: $d_{0}=20 \mathrm{~mm}$, $\Delta r=2 \mathrm{~mm}, \mathrm{l}=57,5 \mathrm{~mm}$ and $\theta=3^{\circ}-$ in nodes $A \& B$
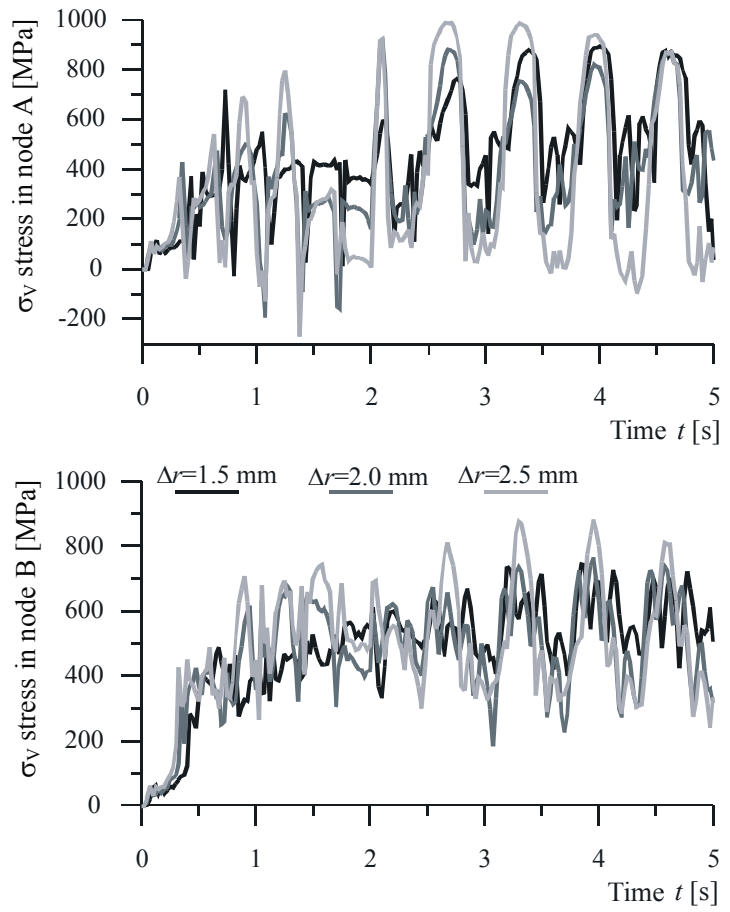

Fig. 8 Influence of bending angle $\theta$ on $\sigma$ v during wasteless splitting process of $C 45$ steel bar at: $d_{0}=20 \mathrm{~mm}$,

$\Delta r=2 \mathrm{~mm}, \mathrm{l}=57,5 \mathrm{~mm}$ and $\alpha=45^{\circ}$ - in nodes $A \& B$

$\sigma_{z r}=\sigma_{V}=\sigma_{1}-\nu\left(\sigma_{2}+\sigma_{3}\right)$

where: $\sigma_{v}$ - de Saint-Venant stress, $\sigma_{1}, \sigma_{2}, \sigma_{3}$ - first, second and third main stress respectively, $\nu$ - Poisson's coefficient [3].

On the basis of calculations, the values of reduced stress in two nodes A (at the beginning placed at $r=7,5 \mathrm{~mm}$ from the bar axis) and $\mathrm{B}$ (for which $r=$ $2,5 \mathrm{~mm}$ ) placed in the plane of the formed necking were analyzed. The obtained distributions of stress $\sigma \mathrm{v}$ in the function of analyzed splitting parameters (angles $\alpha$ and $\theta$ ), reduction ratio $\Delta r$, length $l$ and time $t$ are shown in Figs. 7,8,9,10.

On the basis of calculations it was stated that the change of forming angle $\alpha$ (Fig. 7) influences reduced stress $\sigma_{\mathrm{v}}$ only in $\mathrm{V}$-groove rolling phase, that is for $t<2 \mathrm{~s}$. However, in the rotary bending phase $(t>2 \mathrm{~s})$ distributions of $\sigma_{\mathrm{v}}$ calculated for angles $\alpha=$ $45^{\circ} ; 50^{\circ}$ and $60^{\circ}$ are almost the same. Hence, it can be concluded that the value of angle $\alpha$ does not influence splitting metal cracking course.

Concerning the influence of applied bending angle $\theta$ on reduced stress $\sigma_{\mathrm{v}}$ (Fig. 8) it was stated that the increase of $\theta$ causes considerable increase of 
stress $\sigma_{v}$, both in external layers (point A) and in layers close to axis (point B). However, differences between values $\sigma_{\mathrm{v}}$ for various $\theta$ increase at the further stages of bending. The change of this parameter has, of course, no influence on stress $\sigma_{v}$, noticed at rolling stage of $\mathrm{V}$-groove.

The increase of reduction ratio $\Delta r$ causes considerable increase of reduced stress $\sigma_{v}$ (Fig. 9) both in nodes $\mathrm{A}$ and $\mathrm{B}$. This effect is well visible in the whole process, that is during rolling of $\mathrm{V}$-groove and rotary bending.

Analysis of diagrams shown in Fig. 10 provides interesting information concerning the influence of length $l$ of split billet on reduced stress $\sigma_{\mathrm{v}}$. The shortening of length $l$ causes reduction of stress $\sigma_{\mathrm{v}}$. In the case of billet of length $l=20 \mathrm{~mm}$ the observed stresses $\sigma_{\mathrm{v}}$ (in both analyzed points) did not reach tensile strength value $R_{\mathrm{m}}=697 \mathrm{MPa}$, obtained in tensile test. Hence, in this case the metal will not crack, which was confirmed in experimental tests. Probably, for short billets $\left(l<1,3 . d_{0}\right)$ a different schema of deformation is present, in the result of which bending process is replaced by rotary compression with elongation in axial direction.
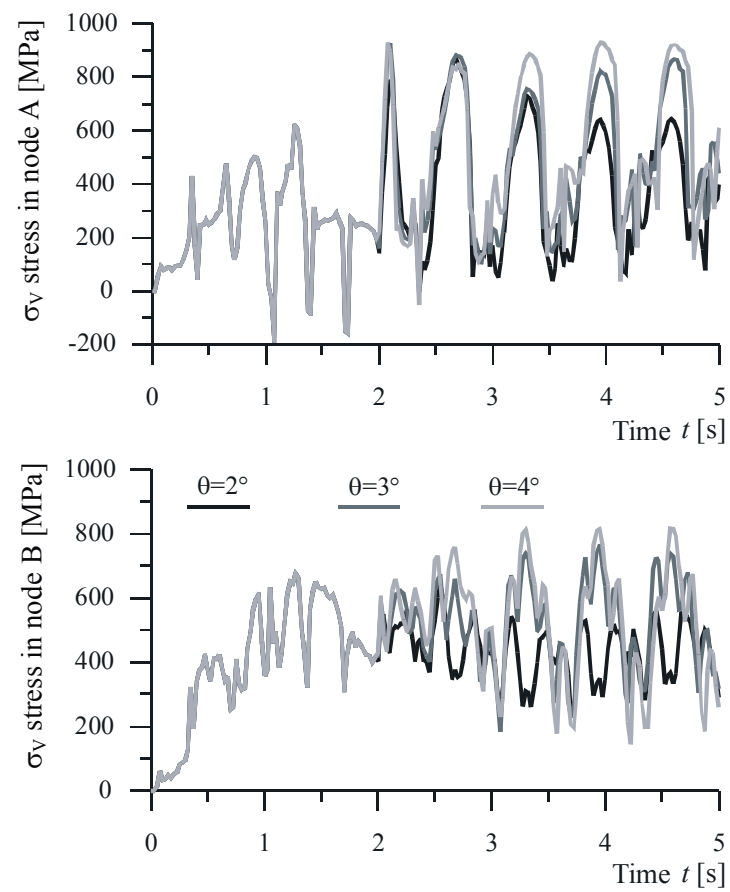

Fig. 9 Influence of rolling depth $\triangle$ ron $\sigma_{v}$ during wasteless splitting process of C45 steel bar at: $d_{0}=20 \mathrm{~mm}, \theta=3^{\circ}$,

$I=57,5 \mathrm{~mm}, \alpha=45^{\circ}$ and - in nodes $A \& B$
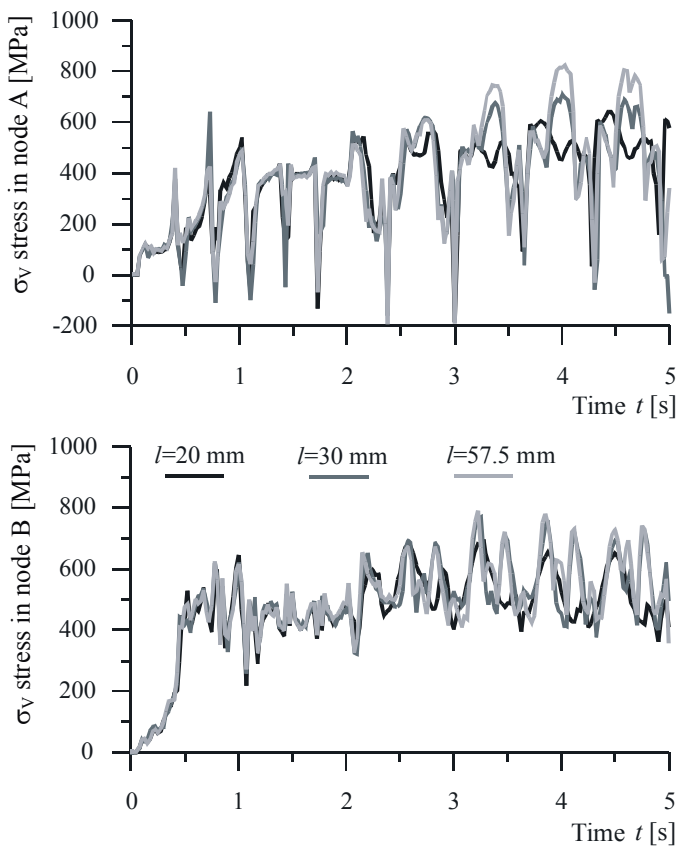

Fig. 10 Influence of length I of separated element on $\sigma \mathrm{v}$ during wasteless splitting process of $C 45$ steel bar at:

$d_{0}=20 \mathrm{~mm}, \theta=3^{\circ}, \triangle r=2 \mathrm{~mm}$ and $\alpha=45^{\circ}$

- in nodes $A \& B$

\section{Ductile fracture}

In the analysis of discards presence, CrocfortLatham criterion was used, defined by the dependency:

$$
\int_{0}^{\varphi^{*}} \sigma_{1} d \varphi=C
$$

where $\sigma_{1}$ - first main stress, $\varphi^{*}$ - limiting strain of cracking, $\varphi i$ - effective strain, $C$ - material constant value.

Conducting of calculations required determining material constant value $\mathrm{C}$ which describes the material cracking moment. In order to do this, authors' method was applied. This method was based on simulation by means of finite element method of tensile test of sample from steel C45 type. Calculations were made till the moment at which relative elongation reached the value $19,1 \%$ (in experimental research at such elongation billets rupture appeared). Next, the value of integral (4) in nodes in critical section was analyzed. Mean results for particular nodes allowed for determining the material constant value which was $\mathrm{C}=0,69$. 
In order to state how the integral Cockroft-Latham value changes in the analyzed splitting process, its distributions in nodes A and B were determined, in which previously values of reduced stress $\sigma_{\mathrm{v}}$ were analyzed. Some of the obtained distributions were presented in Figs. 11, 12. Analysis of calculations results showed that in many cases values of integral (4) not only does not increase during splitting but also decrease. It happens when $\sigma 1$ has negative values. Then, according to equation (4) integral values will decrease. Present in this situation state of 3D compression is favorable for eliminating of micro cracks. Concerning values of integral calculated for nodes A and B it was stated that in any of the analyzed cases it did not exceed the limiting value 0,2 . Hence, in bar cross sections, determined by these points placement unfavorable conditions for metal ductile fracture presence appear.

The influence of forming angle $\alpha$, reduction ratio $\Delta r$ (Fig. 11) and length $l$ of the bar split part on values of integral accumulated in nodes $\mathrm{A}$ and $\mathrm{B}$ is irregular (difficult to determine). Among the analyzed parameters only increasing of bending angle $\theta$ (Fig. 12) causes considerable increase of integral values, which is observed at the whole stage of bending ( $t>2 \mathrm{~s})$.

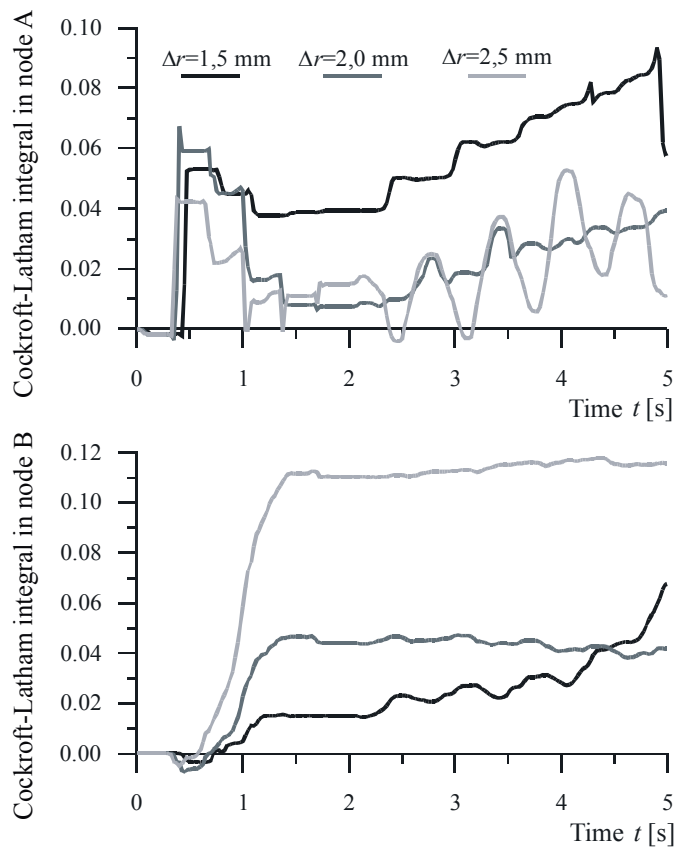

Fig. 11 Influence of rolling depth $\triangle$ r on Cockroft - Latham integral during wasteless splitting process of $C 45$ steel bar at: $\theta=3^{\circ}, I=57,5 \mathrm{~mm}$ and $\alpha=45^{\circ}$ - in nodes $A \& B$
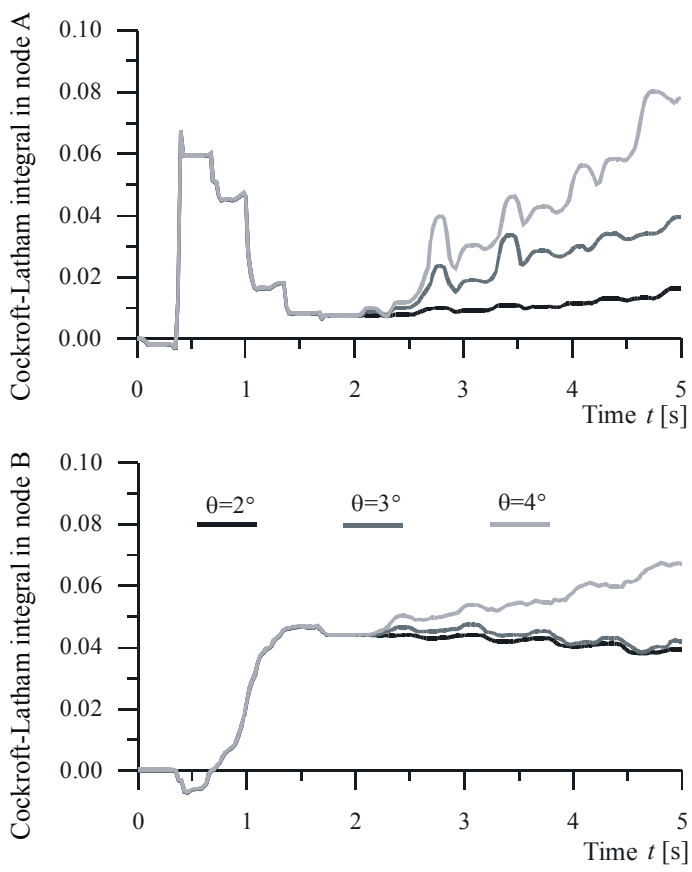

Fig. 12 Influence of bending angle $\theta$ on Cockroft - Latham integral during wasteless splitting process of C 45 steel bar at: $\Delta r=2 \mathrm{~mm}, I=57,5 \mathrm{~mm}$ and $\alpha=45^{\circ}$ - in nodes $A \& B$

\section{Conclusions}

On the basis of research works the following conclusions were drawn:

method of wasteless splitting, basing on crosswedge rolling of $V$-groove and next, rotary bar bending, allow for successful splitting from round metal bar of its part with length I larger than 1.3 bar diameter $d 0$;

bar splitting in the analyzed process of splitting without waste takes place in the result of brittle fracture of metal. State of stress present in the material and strains favors the appearance of ductile rupture;

metal brittle fracture in the process of splitting without waste of round metal bar can be intensified by increasing of bending angle $\theta$ and/or reduction ratio $\triangle r$;

modelling of wasteless splitting process, based on FEM in conditions of 3D state of strain allows for verification of technological and designing parameters of the assumed variants of splitting process; - research works should be continued in order to fully determine technological possibilities of the proposed wasteless splitting process and to work out of an industrial equipment. 


\section{References}

[1] Pater Z., Tofil A. Experimental and theoretical analysis of the cross - wedge rolling process in cold forming conditions. Archives of Metallurgy and Materials 2007 vol. 52, Issue 2 s. 289 $-297$

[2] Tofil A. Research of process of mechanical splitting without waste of round metal bars. Ph. D. Thesis, Lublin University of Technology, Lublin 2008 (in Polish)

[3] Pełczyński W. T., Pełczyński T. A. Teoria procesów obróbki plastycznej. Część I Mechanika obróbki plastycznej. Warsaw University of Technology, Warsaw 1982 (in Polish)

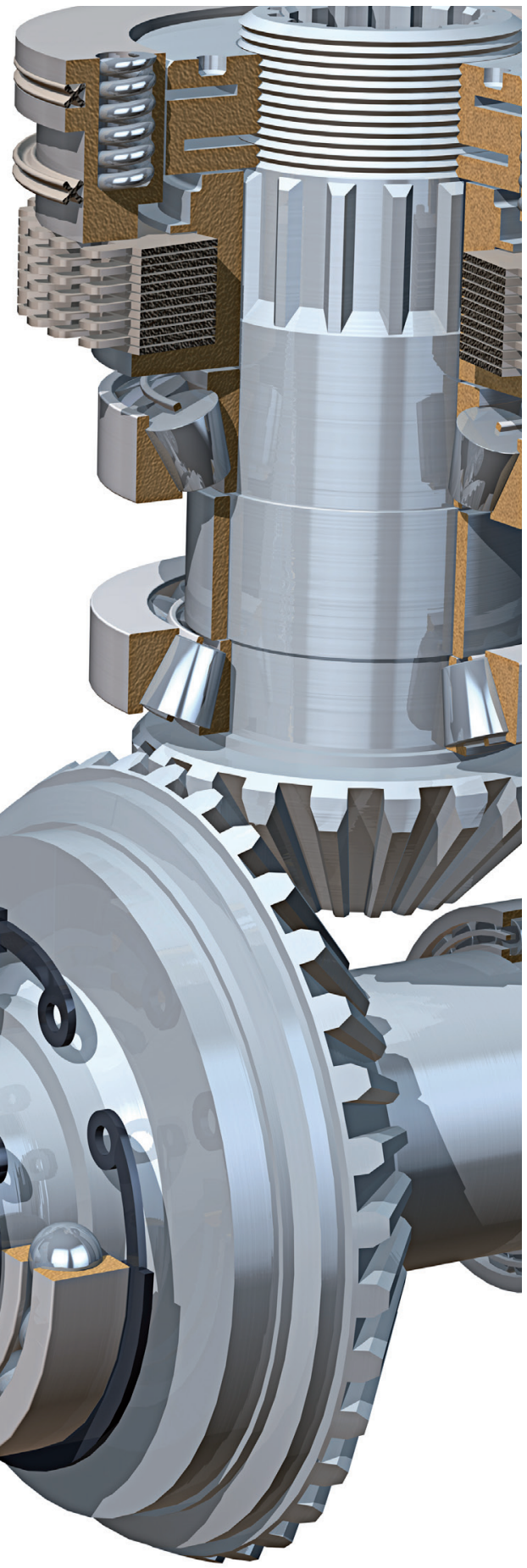

